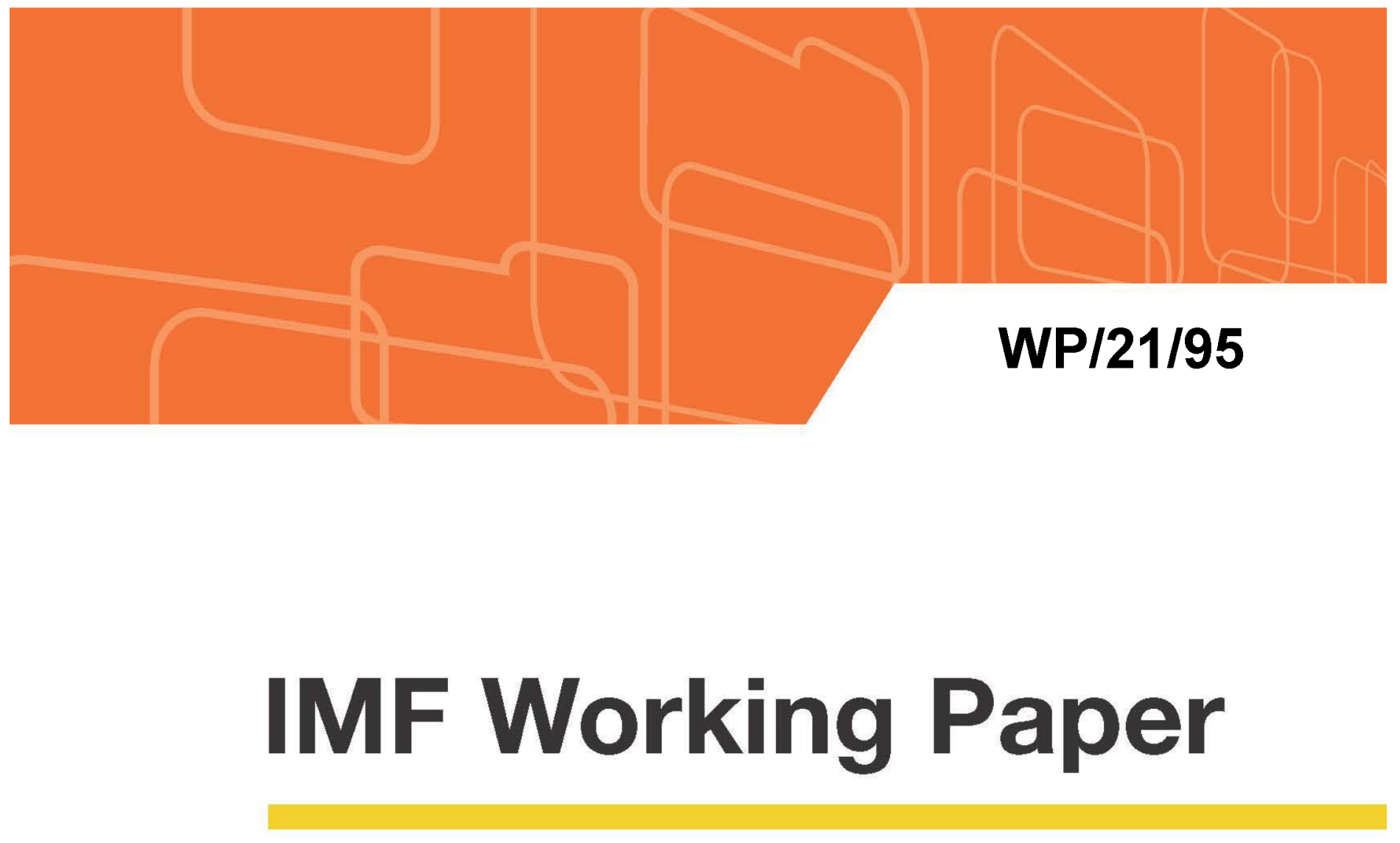

\title{
Gender and Employment in the COVID-19 Recession: Evidence on "She-cessions"
}

\author{
John Bluedorn, Francesca Caselli, Niels-Jakob Hansen, \\ Ippei Shibata, and Marina M. Tavares
}

IMF Working Papers describe research in progress by the author(s) and are published to elicit comments and to encourage debate. The views expressed in IMF Working Papers are those of the author(s) and do not necessarily represent the views of the IMF, its Executive Board, or IMF management. 


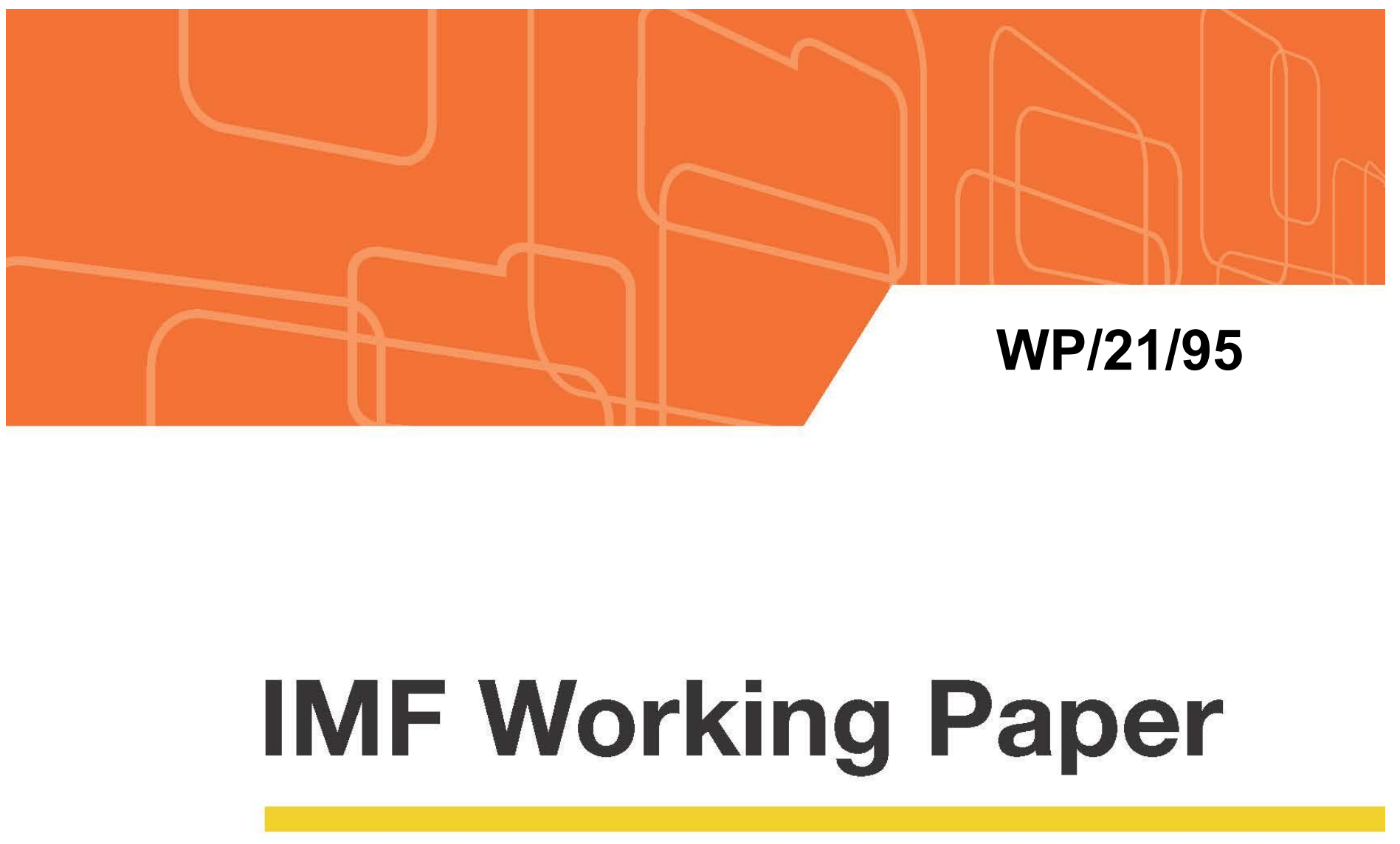

\title{
Gender and Employment in the COVID-19 Recession: Evidence on "She-cessions"
}

\author{
John Bluedorn, Francesca Caselli, Niels-Jakob Hansen, \\ Ippei Shibata, and Marina M. Tavares
}

IMF Working Papers describe research in progress by the author(s) and are published to elicit comments and to encourage debate. The views expressed in IMF Working Papers are those of the author(s) and do not necessarily represent the views of the IMF, its Executive Board, or IMF management.

I N T E R N A T I O N A L M O N 


\title{
IMF Working Paper
}

Research Department

\begin{abstract}
Gender and Employment in the COVID-19 Recession: Evidence on "She-cessions" Prepared by John Bluedorn, Francesca Caselli, Niels-Jakob Hansen, Ippei Shibata, and Marina M. Tavares ${ }^{1}$
\end{abstract}

Authorized for distribution by Malhar Nabar

March 2021

\section{IMF Working Papers describe research in progress by the author(s) and are published to} elicit comments and to encourage debate. The views expressed in IMF Working Papers are those of the author(s) and do not necessarily represent the views of the IMF, its Executive Board, or IMF management.

\begin{abstract}
Early evidence on the pandemic's effects pointed to women's employment falling disproportionately, leading observers to call a "she-cession." This paper documents the extent and persistence of this phenomenon in a quarterly sample of 38 advanced and emerging market economies. We show that there is a large degree of heterogeneity across countries, with over half to two-thirds exhibiting larger declines in women's than men's employment rates. These gender differences in COVID-19's effects are typically short-lived, lasting only a quarter or two on average. We also show that she-cessions are strongly related to COVID-19's impacts on gender shares in employment within sectors.
\end{abstract}

JEL Classification Numbers: E24, E32, J16

Keywords: COVID-19 recession, Employment, Gender

Author's E-Mail Address: jbluedorn@imf.org, fcaselli@imf.org, nhansen@,imf.org, ishibata@imf.org, mmendestavares@,imf.org

\footnotetext{
${ }^{1}$ International Monetary Fund Research Department. 700 19th St NW, Washington, DC 20431, USA. We thank Gita Gopinath, Petya Koeva Brooks, and Malhar Nabar for insightful comments. We also thank Youyou Huang, Yi Ji, and Cynthia Nyakeri for excellent research assistance. The views expressed in this Working Papers are those of the authors and do not necessarily represent the views of the IMF, its Executive Board, or IMF management.
} 


\section{INTRODUCTION}

The pandemic is having very unequal effects across socioeconomic groups with vulnerable workers more at risk of losing their jobs (Chetty and others 2020, IMF 2021). More specifically, a growing literature has been examining the differences in labor market consequences of the COVID-19 crisis by gender. Many recent studies have argued that the crisis is causing a "she-cession," where women's labor market outcomes and prospects have deteriorated disproportionately (Albanesi and Kim 2021, Alon and others 2020, Caselli and others 2020, Fabrizio and others 2021, and Shibata 2020, among others). This pattern contrasts with the "man-cession" observed after the global financial crisis in which men appeared to be much more heavily impacted, according to U.S. studies (Wall 2009; Hoynes, Miller, and Schaller 2012).

There has been vigorous debate on the underlying drivers of the COVID-19 crisis's asymmetric labor market impact by gender, with several factors cited. First, women's employment shares are higher in contact-intensive sectors which have been more severely affected (Mongey, Pilossoph, and Weinberg 2020 and Albanesi and Kim 2021). Second, women tend to carry a higher childcare burden when schools are closed (Adams-Prassal and others 2020, Fuchs-Schündeln and others 2020, Hupkau and Petrongolo 2020, Russell and Sun 2021, and Zamarro and Prados 2020). Third, women are more often employed in temporary and part-time jobs that are more at risk of being terminated in a downturn (Petrongolo 2004 and Bahn and Sanchez Cumming 2020). All these factors contributed to the she-cession in the first months of the pandemic, with women's unemployment rising disproportionately more than that of men in several countries.

While most studies discussing the pandemic's economic consequences by gender focus on the U.S. or a few advanced economies, this paper examines the labor market impacts of the COVID-19 crisis by gender at quarterly frequency for a large panel of 30 advanced economies and 8 emerging market economies, expanding upon the aggregate findings on gender differences by economy group of IMF (2021) and making three key contributions. First, we document the extent and persistence of COVID19 crisis-related she-cessions across countries within 2020, where a she-cession is called for a quarter in 2020 when there is a negative difference between women's and men's employment rate (employment-to-population ratio) changes compared with 2019 (that is, women are losing more jobs than men as a share of population). Second, we quantify the role of sectoral employment composition in gender differences in labor market outcomes. Third, we further elaborate on recent labor market dynamics by gender, examining the relative importance of the intensive versus extensive margins by gender (average hours worked versus employment) and movements in unemployment versus labor force participation that underlie employment changes by gender.

We find that over half to two-thirds of the countries in our sample experienced she-cessions in 2020:Q2, depending on whether the gap change is gauged as a percentage point or percent change. By contrast, only about 8 percent of the countries in our sample experienced a she-cession during the depths of the global financial crisis (2009:Q2). Moreover, the COVID-19 crisis she-cessions tend to be short-lived, fading by 2020:Q3 for three-fifths to two-thirds of countries.

The analysis of sectoral employment patterns reveals that COVID-19 she-cessions are associated with drops in women's sectoral employment shares, particularly in sectors accounting for more of women's total employment. For countries where we have sectoral employment by gender, almost all of those which experienced she-cessions were predominantly driven by declining women's shares in employment within sectors.

The employment rate is a standard measure of overall labor market conditions that captures the extensive margin of labor utilization. However, it can mask changes in other margins that may be of 
interest. The employment rate misses labor market adjustments in hours worked (the intensive margin of labor), which could be significant with the widespread deployment of short-term work schemes to preserve job links while enabling reductions in employers' labor costs through reductions in working hours (Giupponi and Landais 2020; IMF COVID-19 Policy Tracker). The labor force participation margin may be particularly important in understanding the consequences of the COVID-19 recession by gender. ${ }^{2}$ As noted before, women may have opted out of the labor market in greater numbers to care for their children who are not in school. Moreover, early in the COVID-19 recession, entire sectors had to shut down, leading some laid-off workers to simply cease participating in the labor market (Coibion, Gorodnichenko, and Weber 2020). ${ }^{3}$

We find that men have typically seen average hours worked fall by more than women in our sample of countries. She-cession gender gap changes in the first three quarters of 2020 are far more evident along the extensive margin (employment) than the intensive margin (average hours worked). Shecession gender gap changes more often reflected larger declines in women's than men's labor force participation rates than relative rises in women's unemployment rates. The average narrowing of shecession gender gap changes in employment as of 2020:Q3 appears to arise from both relative improvements in labor force participation by women and shrinking of unemployment rate differences.

Understanding and unpacking the heterogeneity and persistence of the pandemic's effect by gender are essential to assessing both the short-term and potential medium-term effects of the crisis. The consequences for job losers can be dire, as they face earnings losses and difficulties in finding a job after unemployment spells, leading to some scarring (IMF 2021). Policies to support adversely impacted workers over the near term — such as wage subsidies - can help mitigate these losses. Women's employment may also be particularly sensitive to measures that help alleviate childcare burdens (Vuri 2016). Even after the pandemic abates, some of the effects on the structure of employment may persist, with some sectors permanently shrinking and others growing. For these persistent effects, the speed with which economies can reemploy and reallocate impacted workers across sectors - for example, through training and hiring incentives - will determine how long-lived the effects on employment are. Recent studies pointing to the productivity increases associated with gender diversity at all levels of the workforce suggest that targeting gender gaps specifically could generate a double benefit: improvements in overall labor market conditions and a productivity boon (Elborgh-Woytek and others 2013; Gonzales and others 2015).

There are some potential channels by which the COVID-19 recession could have long-lasting, asymmetric adverse effects on women's prospects that may not be visible in recent employment trends. Some recent survey results suggest that women are more likely to be rethinking career decisions in light of the pandemic (Romei 2021), which could mean that the crisis leads to a future drop in women's labor force participation. Moreover, career interruptions that fall more heavily on women from the COVID-19 crisis could adversely impact their longer-term earnings and employment prospects (Albrecht and others 1999, Aisenbrey, Evertsson, and Grunow 2009).

The rest of the paper is organized as follows. Section 2 describes the data and the definition of shecession used throughout the paper. Section 3 presents the baseline results on employment rates by gender. Section 4 explores sectoral employment differences as a driver of COVID-19 she-cessions.

\footnotetext{
${ }^{2}$ Blau and Khan (2013) and Goldin (2015) find that women tend to have more fragile labor force attachment and be at greater risk of dropping out of the labor force when they experience adverse shocks.

${ }^{3}$ Based on a large-scale survey of US households, Coibion, Gorodnichenko, and Weber (2020) find that many workers who lost their job during the COVID-19 recession are not actively looking for jobs, suggesting a large fall in labor force participation.
} 
Section 5 examines gender gaps along alternative labor margins, including hours worked, labor force participation, and unemployment. Section 6 reports some robustness exercises using an alternative she-cession measure. Section 7 concludes.

\section{SHE-CESSIONS: DATA AND DEFINITION}

Our analysis relies on a mix of OECD and Eurostat labor market data, harmonized within analytical exercise at quarterly frequency. The employment rate (employment-to-population ratio) and the unemployment rate (number of unemployed relative to the labor force, defined as the sum of employed and unemployed workers) by gender and age are available for 38 countries at the quarterly frequency from the OECD, with 30 advanced economies and 8 emerging market economies in the sample. For the sectoral analysis of employment by gender, quarterly data from Eurostat are used, covering 19 European countries with populations over 2 million inhabitants. Average hours worked are also available for European countries only. The analysis ends in 2020:Q3 due to data availability. Table A1 shows the list of countries and the samples used across the different exercises.

We start by presenting the evolution of the employment rate by gender over 2020, with respect to 2019. There is a sharp drop in the median country's employment rate in 2020:Q2 for both women and men (Figure 1, panel a). This is not surprising as this period coincides with the beginning of the pandemic and the introduction of strict containment measures by most countries in our sample. Women's employment rate falls by around 1.7 percentage points and men's by around 1.6 percentage points from their average levels in 2019. When gauged using the percent change in the employment rate relative to 2019, the declines are about 2.5 percent for women and about 2 percent for men, suggesting a larger difference if base effects (lower preexisting employment rates for women) are incorporated (Figure 1, panel b).

Figure 1. Employment Rate By Gender Over 2020

(Deviation from 2019 average)

Panel (a) - Percentage point change

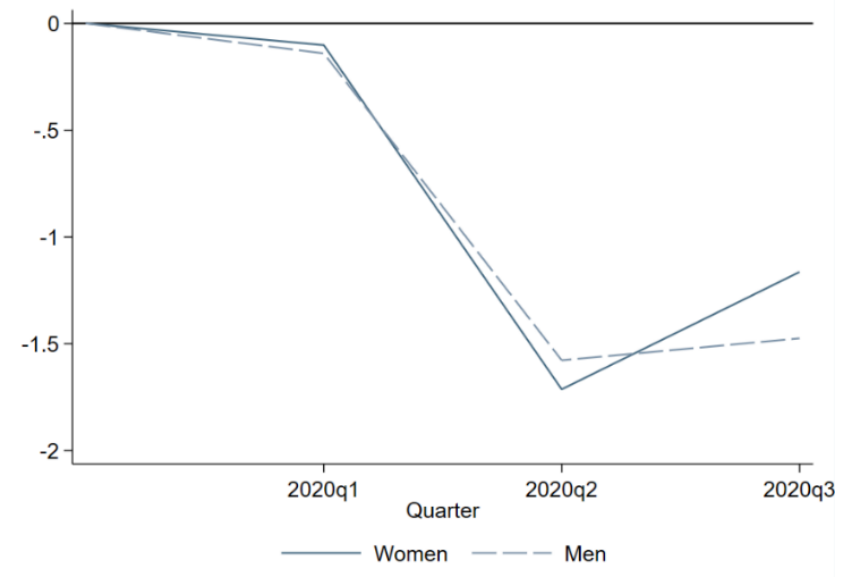

Panel (b) - Percent change

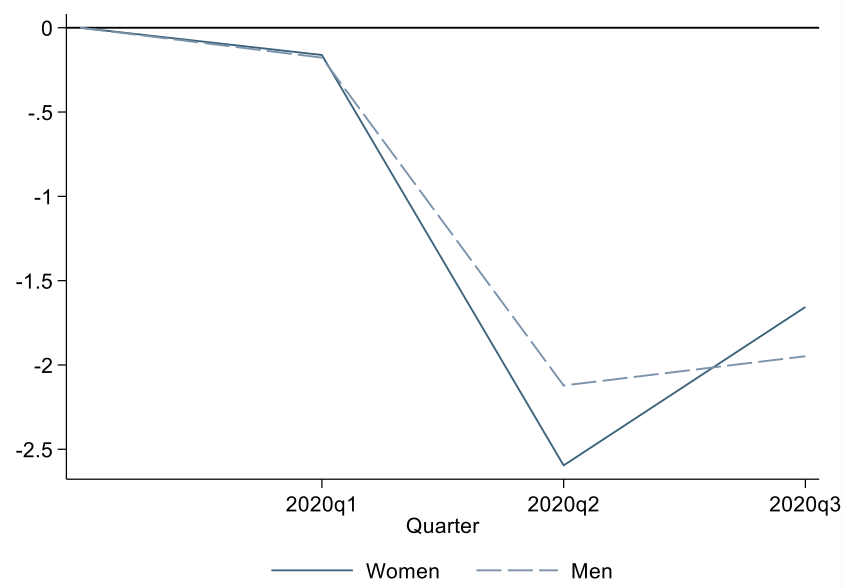

Note: The chart reports the evolution of the ratio of employment to population by gender with respect to their 2019 averages. The sample includes 38 advanced and emerging market economies. Panel (A) reports the percentage point deviation as shown Equation (1) and Panel (B) exhibits the percent change as shown in Equation (2).

While the trough of the two median series appears to be in 2020:Q2, women's employment rate tends to recover faster in 2020:Q3. This might be due to reopening of some of the hardest hit sectors, such as hospitality and personal care, in 2020:Q3 as containment measures were relaxed. Similarly, in many of the countries in our sample, schools reopened in the third quarter of 2020. Since 2020:Q2 
represents the trough of the average employment series for both men and women, we focus on labor market differences.

We consider two possible definitions for a she-cession, based on alternative measures of the change in employment rates by gender. The first is based on the percentage point difference in the change in women's and men's employment rates:

$$
\Delta e_{t, 2019 a v g}^{D i f f, W-M}=\left(e_{t}^{W}-e_{2019 a v g}^{W}\right)-\left(e_{t}^{M}-e_{2019 a v g}^{M}\right)
$$

where $e_{2019 \mathrm{avg}}^{W}$ and $e_{2019 \mathrm{avg}}^{M}$ are the average employment rates in 2019 based on quarterly data for women and men respectively and $e_{t}^{W}$ and $e_{t}^{M}$ are the employment rates by gender by quarter in 2020 . The second is based on the difference in the percent changes of women's and men's employment rates:

$$
\Delta e_{t, 2019 \text { avg }}^{\text {Diff } R-M}=\left(\frac{e_{t}^{W}}{e_{2019 a v g}^{W}}\right)-\left(\frac{e_{t}^{M}}{e_{2019 a v g}^{M}}\right)
$$

where all the components are defined as above. The measure in equation (1) is the absolute difference in employment rate changes or absolute gender gap change, while that in equation (2) captures the relative difference in employment rate changes or relative gender gap change, since it incorporates possible base effects from women's typically lower employment rates. With either measure, a shecession is called if the gender gap change $\left(\Delta e_{t, 2019 a v g}^{\cdot, W-M}\right)$ is negative (women's drop in employment is greater than men's).

\section{The EXTent ANd Persistence of COVID-19 She-Cessions ACross Countries}

Focusing on the she-cession gender gap change in the trough observed in 2020:Q2, we see a striking degree of heterogeneity across countries with just over half of the sample experiencing she-cessions according to the absolute gender gap change measure (Figure 2). This pattern also appears within the subset of emerging market economies in our sample, with Poland, Hungary, Lithuania, and Colombia experiencing a she-cession while Turkey, South Africa, Russia, and Chile saw men's employment rates hit harder than women's. Moreover, there is significant variation in the severity of she-cessions, with Canada and Iceland having absolute gender gap changes of more than 1 percentage point, followed by Poland, Sweden, Finland, New Zealand, and Lithuania.

About 40 percent of the economies experiencing she-cessions had she-cession gender gap changes of a half percentage point or more (or about a fifth of all economies in the sample). She-cessions are not a universal phenomenon and moreover, their severity differs markedly. There is a high degree of heterogeneity in experiences, across both advanced and emerging market economies.

The broad pattern of she-cessions is also evident if the relative gender gap change measure in equation (2) is used (Figure 3). By this metric, about two-thirds of economies were experiencing shecessions in 2020:Q2. The higher incidence captured by the difference in percent change of employment rates reflects the base effects of women's typically lower employment rates. 
Figure 2. She-cession Absolute Gender Gap Changes Across Economies (2020:Q2) (Percentage point change)

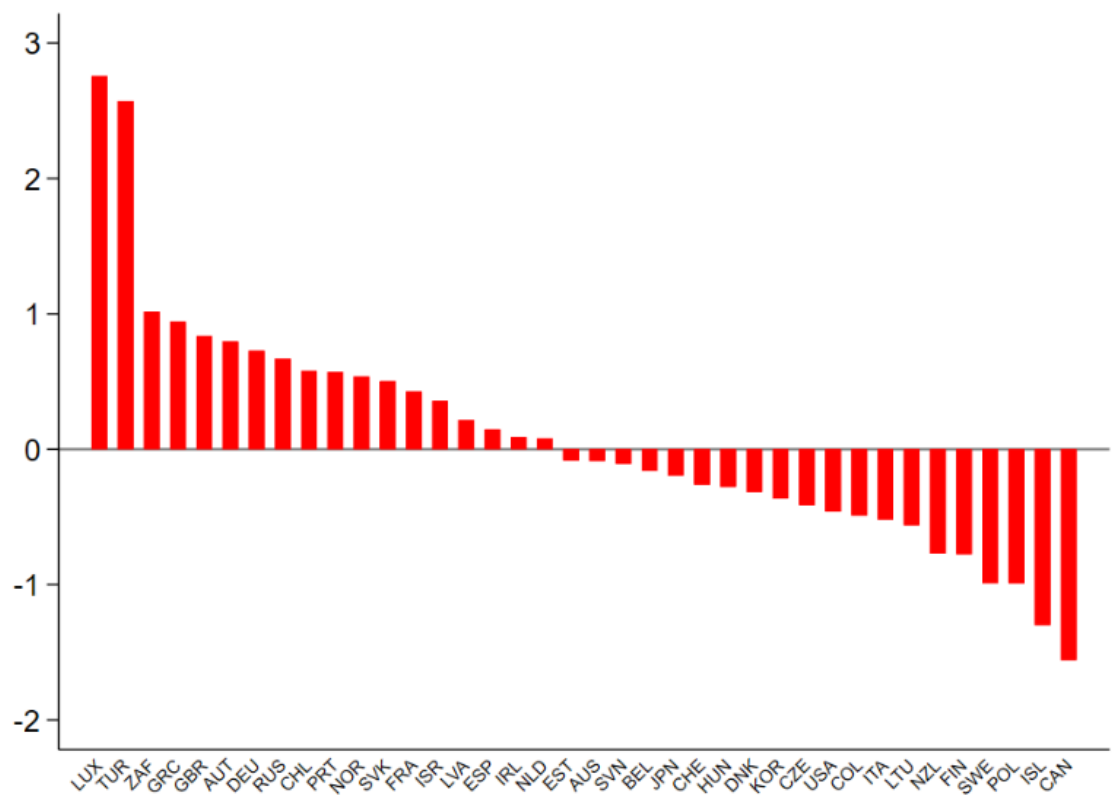

Note: The chart reports the gap in employment rate changes between women and men as defined by Equation (1). A negative value corresponds to a she-cession.

Figure 3. She-cession Relative Gender Gap Changes Across Economies (2020:Q2) (Percent change)

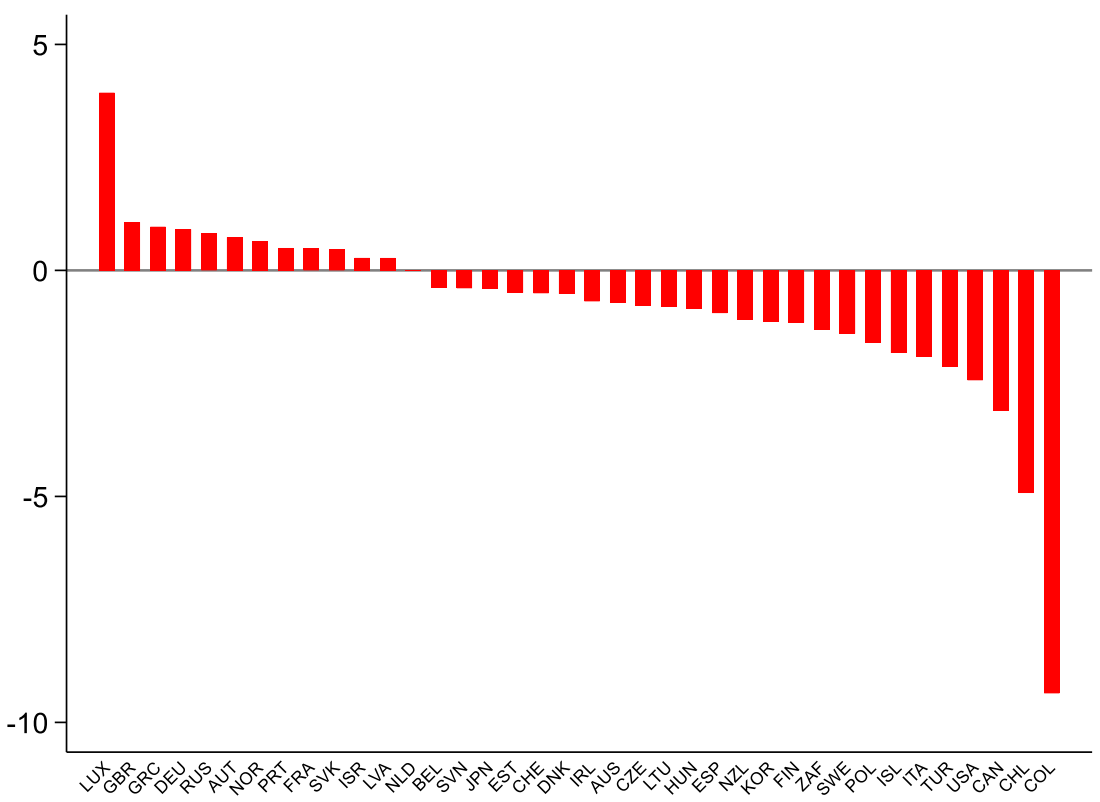

Note: The chart reports the gap in employment rate changes between women and men as defined by Equation (2). A negative value corresponds to a she-cession. 
We now analyze the persistence of the she-cession through 2020. Figure 4 reports the median and the $25^{\text {th }}$ and $75^{\text {th }}$ percentiles of the gender gap change (absolute or relative) up to the third quarter of 2020 (due to data availability). First, we observe that the median country in our sample experienced a shecession in 2020:Q2, but these subsided for the median country by 2020:Q3 for both measures.

Second, as stressed before, there is sizable dispersion across countries.

Figure 4. COVID-19 She-cessions Over Time

Panel (a) - Percentage point change

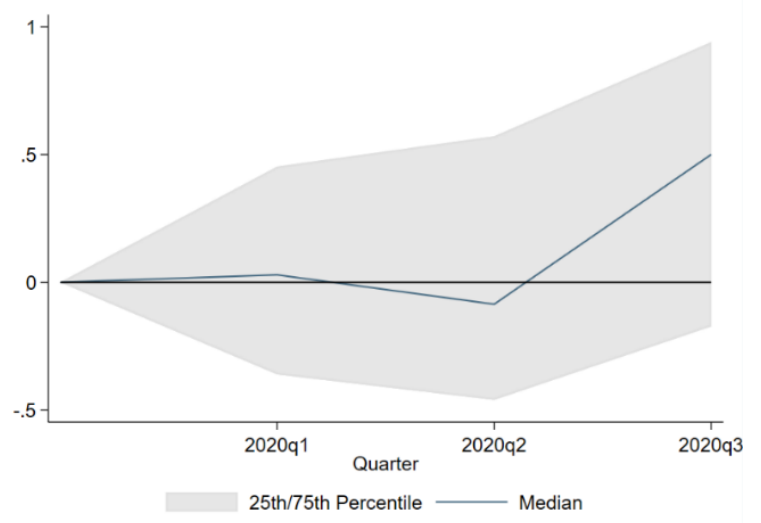

Panel (b) - Percent change

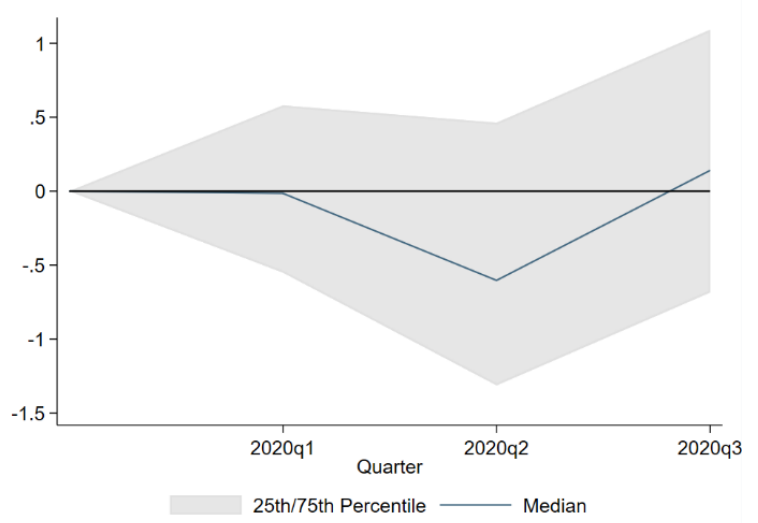

Note: The chart reports the evolution of the gap between women and men employment to population ratio with respect to the 2019 average. The solid line corresponds to the median and the shaded areas to the interquartile ranges. The sample includes 38 advanced and emerging market economies.

Unpacking these patterns, Table 1 shows that 53 percent of countries in our sample experienced a she-cession in 2020:Q2. By 2020:Q3, however, only 32 percent of the sample countries were in a shecession, where the gender gap change remained negative. A similar pattern is visible when focusing only on emerging market economies, with 50 percent of countries in she-cession in the second quarter and around 38 percent by the third quarter. However, even as the COVID-19 shock's exacerbation of the gender gap abates, the preexisting gender gaps between the levels of men's and women's employment rates may still remain.

This picture constrasts with the one that emerges from the analysis of the global financial crisis. When we do the same exercise using the absolute gender gap change, but comparing 2009:Q2 with the 2007 average, we find that only 8 percent of countries experienced a she-cession. By 2009:Q3 only 5 percent of the countries in our sample were in a she-cession. This evidence is consistent with studies of the US labor market during the global financial crisis which found that men were more heavily impacted by the crisis (Wall 2009 and Hoynes, Miller, and Schaller 2012).

\section{Table 1. Fraction of Economies with She-cessions} (based on absolute gap change)

\begin{tabular}{|c|c|c|c|}
\hline Quarter & All & AEs & EMs \\
\hline 2020:Q2 & 0.53 & 0.53 & 0.50 \\
\hline 2020:Q3 & 0.32 & 0.30 & 0.38 \\
\hline
\end{tabular}

Note: The table reports the fraction of countries with negative absolute gender gap changes (Equation (1) she-cessions) by quarter for the full sample.

The relative gender gap change metric shows a similar pattern over time, with 68 percent of countries in our sample in 2020:Q2 experiencing a she-cession (Table 2). This declines to about 45 percent by 
2020:Q3. The reduction in she-cession incidence over time also holds across economy groups, but with a larger drop showing up in advanced economies.

Table 2. Fraction of Economies with She-cessions (based on relative gap change)

\begin{tabular}{lrrrr}
\hline \hline Quarter & \multicolumn{1}{l}{ All } & \multicolumn{2}{l}{ AEs } & \multicolumn{2}{l}{ EMs } \\
\hline 2020:Q2 & & 0.68 & 0.63 & 0.88 \\
2020:Q3 & & 0.45 & 0.37 & 0.75 \\
\hline \hline
\end{tabular}

Note: The table reports the fraction of countries with negative relative gender gap changes (Equation (2) she-cessions) by quarter for the full sample.

\section{The Role of Sectoral Workforce CoMposition In THE COVID-19 PANDEMIC'S ASYMMETRIC EMPLOYMENT IMPACTS BY GENDER}

Two factors could be driving the uneven impact of the current crisis on women: (i) women tend to have higher preexisting employment shares in sectors particularly hit by the COVID-19 crisis, and (ii) within a given sector women tend to experience worse labor market outcomes. To better understand the role of the gender distribution of employment across sectors, we investigate sectoral employment composition by gender for the set of countries in our sample for which we have quarterly employment data broken down by gender and sector (Table A1). The sample includes 20 European countries.

Ordered by the pre-crisis sectoral share of women's employment, we observe that some of the sectors experiencing the largest drops in employment accounted for substantial shares of women's employment. More specifically, the ratio of employment to population in sectors with a larger share of women's employment fell by about 0.11 percentage points on average from their average level in 2019 to 2020:Q2, while sectors with a higher share of men's employment fell slightly less, by an average of 0.07 percentage points as of 2020:Q2. For instance, the accommodation and food sector, which accounts for 6.5 percent of women's employment, saw its employment-to-population ratio decline by a 0.62 percentage points on average during the pandemic. The wholesale and retail sector, accounting for 13.7 percent of women's employment, saw its ratio drop by 0.42 percentage points by 2020:Q2. By contrast, the construction sector's employment-to-population ratio, where 11.1 percent of employed men have jobs, only fell by 0.17 percentage points on average. These dynamics suggest that sectors employing more women typically experienced worse outcomes compared with sectors accounting for larger shares of men's employment (Figure 5). 
Figure 5: Sectoral Employment Changes as of 2020:Q2 and Pre-Crisis Sectoral Shares of Women's Employment

(Percentage points, left and percent, right)

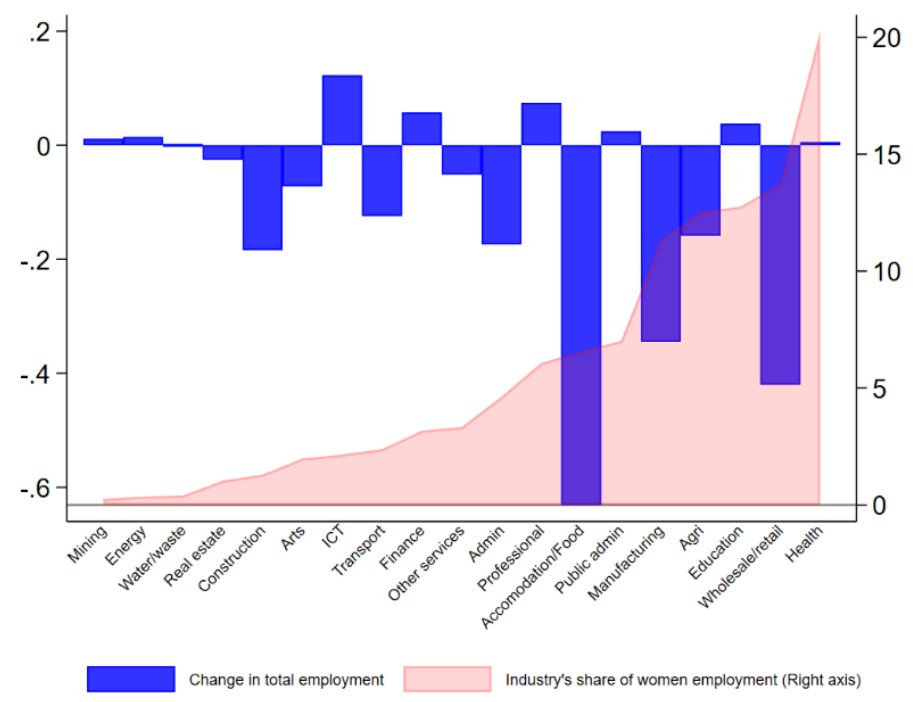

Note: The chart reports the change in employment-to-population ratios between 2020:Q2 and 2019 and the share of women's employment in each NACE Rev. 4 sector as of 2019. The reported employment changes and sectoral shares are weighted averages of underlying country-by-country changes and sectoral shares with total employment used as weights.

Figure 6 shows that women in some sectors have been harder hit than men. An extreme example is the health sector, where employment for men increased by 0.14 percentage points, while women's employment fell by 0.14 percent. Conversely, women's employment increased within construction and public administration, while it fell for men. Overall, in 9 sectors women's employment fell by more than men's, while the opposite is true in 10 sectors. 
Figure 6: Sectoral Employment Changes By Gender (2020:Q2 versus 2019) (Percentage points)

Panel (a) - By Gender

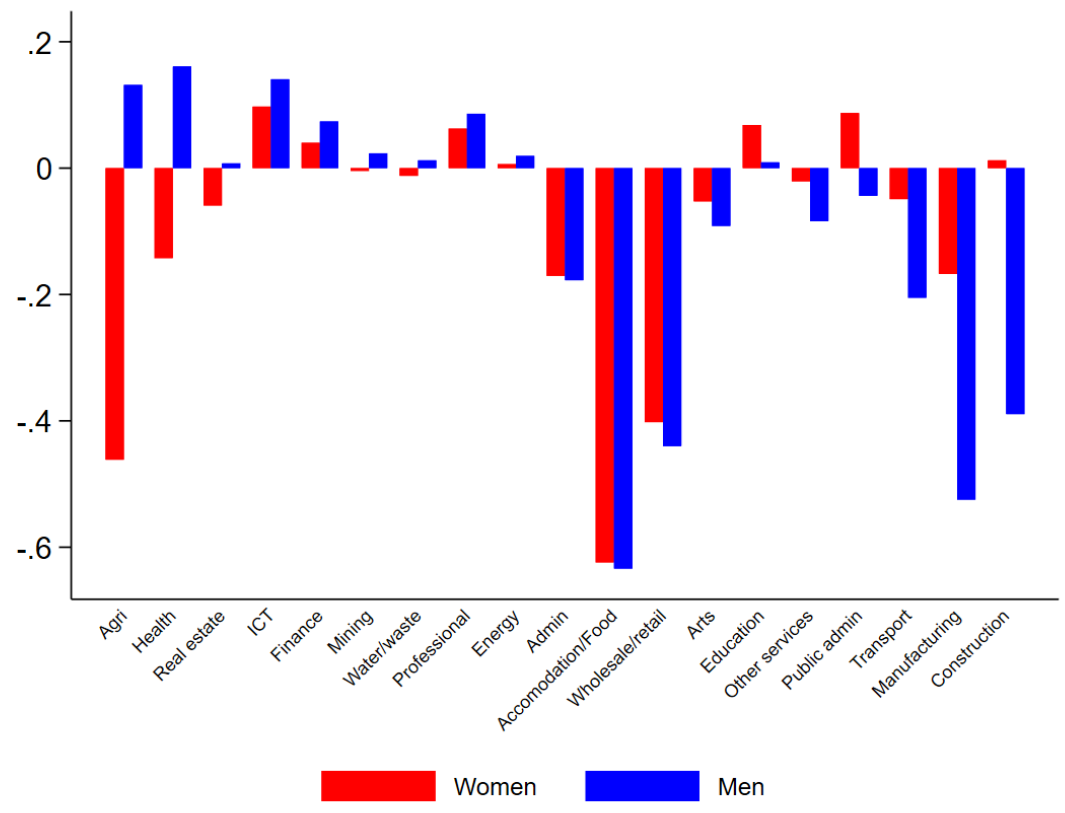

Panel (b) - absolute difference (Women less Men)

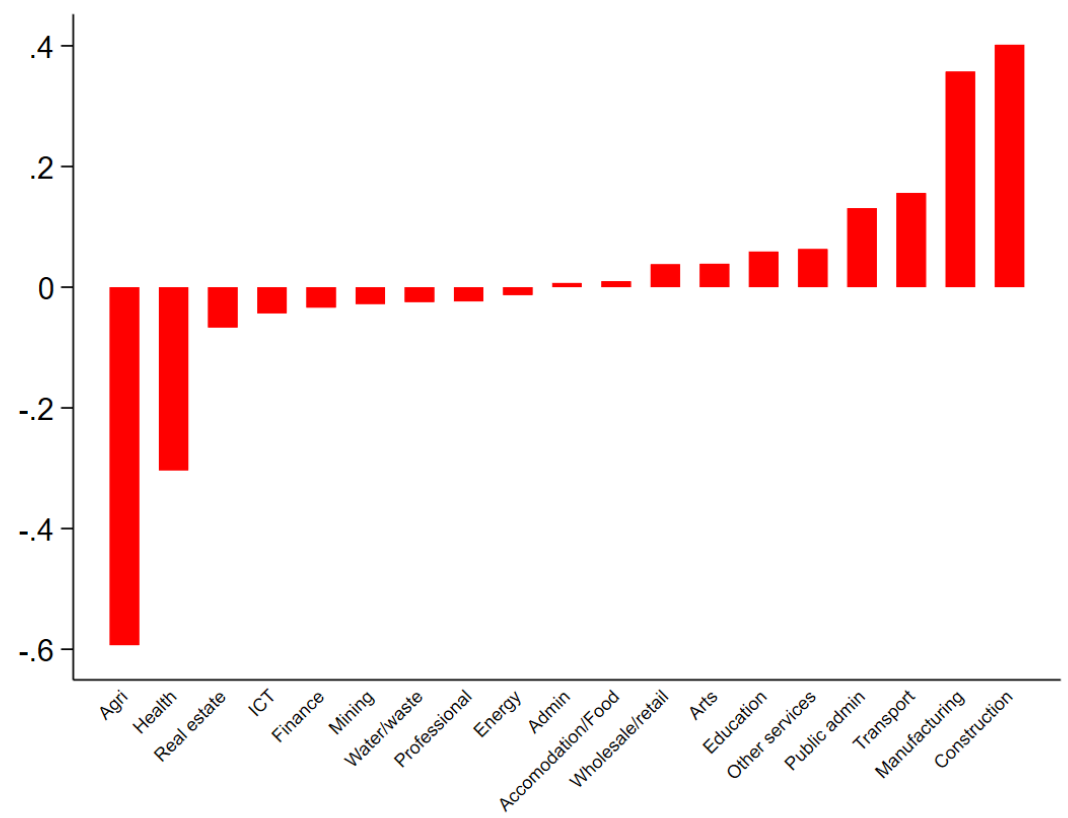

Note: The chart reports the employment change in 2020:Q2 with respect to the average in 2019 by NACE Rev. 4 sector. Panel (A) shows the percent changes in employment by gender. Panel (B) shows the average gender gap changes. The reported employment changes are weighted averages of underlying country-bycountry changes with total employment used as weights. 
To quantify the roles of changing gender shares and sectoral employment changes, we focus on the absolute gender gap change during the pandemic and decompose it into two components:

$$
\begin{aligned}
\left(e_{t+1}^{w}-e_{t}^{w}\right)- & \left(e_{t+1}^{m}-e_{t}^{m}\right) \\
= & {\left[\left(e_{t+1}^{w}-\sum_{s} \omega_{s, t}\left(\frac{E_{s, t+1}}{P_{t+1}^{w}}\right)\right)-\left(e_{t}^{w}-\sum_{s} \omega_{s, t}\left(\frac{E_{s, t+1}}{P_{t+1}^{w}}\right)\right)\right] } \\
& -\left[\left(e_{t+1}^{m}-\sum_{s}\left(1-\omega_{s, t}\right)\left(\frac{E_{s, t+1}}{P_{t+1}^{m}}\right)\right)-\left(e_{t}^{m}-\sum_{s}\left(1-\omega_{s, t}\right)\left(\frac{E_{s, t+1}}{P_{t+1}^{m}}\right)\right)\right] \\
= & \underbrace{\left[\left(\sum_{s} \omega_{s, t}\left(\frac{E_{s, t+1}}{P_{t+1}^{w}}-\frac{E_{s, t}}{P_{t}^{w}}\right)\right)-\left(\sum_{s}\left(1-\omega_{s, t}\right)\left(\frac{E_{s, t+1}}{P_{t+1}^{m}}-\frac{E_{s, t}}{P_{t}^{m}}\right)\right)\right]}_{\text {change in gender share }} \\
+ & \underbrace{\left[\left(\sum_{s}\left(\omega_{s, t+1}-\omega_{s, t}\right)\left(\frac{E_{s, t+1}}{P_{t+1}^{w}}\right)\right)-\left(\sum_{s}\left(\omega_{s, t}-\omega_{s, t+1}\right)\left(\frac{E_{s, t+1}}{P_{t+1}^{m}}\right)\right)\right]}_{\text {changectoral employment }}(2)
\end{aligned}
$$

where $e_{t}^{w}$ and $e_{t}^{m}$ denote women's and men's employment rates at time $t, \omega_{s, t}$ denotes women's share of employment in sector $s$ at time $t, E_{s, t+1}$ is total employment in sector $s$ at time $t+1$, and $P_{t+1}^{w}$ and $P_{t+1}^{m}$ are the working-age populations of women and men, respectively, at time $t+1$. For the COVID-19 crisis, we take $t$ to indicate the average value of the variable over 2019 and $t+1$ to indicate the value of the variable in 2020:Q2, giving us the difference in the percentage point change of employment rates by gender over the first half of 2020. Recall that the employment rate for a given population $x \in\{w, m\}$ is defined as $e_{t}^{x}=\frac{E_{t+1}^{x}}{P_{t+1}^{x}}$ and note that $E_{t+1}^{w}=\sum_{s} \omega_{s, t+1} E_{s, t+1}$ and $E_{t+1}^{m}=$ $\sum_{s}\left(1-\omega_{s, t+1}\right) E_{s, t+1}$.

The first squared bracket on the righthand side then represents the employment effect stemming from changes in sectoral employment holding fixed women's employment shares by sector. This captures the consequences of women's higher preexisting employment shares in sectors particularly hit by the COVID-19 crisis. The second squared bracket on the righthand side represents the effect of changes in gender shares of employment within sectors. This captures the extent to which women's employment is hit harder than men's within sectors.

Figure 7 shows this decomposition for each country in our sample. The grey dot corresponds to the gender gap change, the blue bar to the component due to the change in gender share, and the red one to the component due to the change in sectoral employment. A negative value in this chart indicates that the relevant factor contributed to a more negative impact for women than for men, while a positive factor means that the relevant factor contributed to a more negative impact for men than women. Consistent with the previous analysis, about half of the countries ( 9 out of 20 in the sample) appear to be in she-cession - that is, the change in the overall gender gap in employment rates is negative. In 8 countries out of these 9 countries, changes in gender shares of sectoral employment are the driving factor of the she-cession. Annex Figure A.1 shows the same decomposition for the period 
2019 (average) to 2020:Q3 (rather than 2020:Q2). For this period 7 out of 18 countries $^{4}$ appears to be in she-cession, and in 5 out of these 7 countries changes in gender shares of sectoral employment are the driving factor of the she-cession. Similar patterns are also visible with a sectoral decomposition for the relative gender gap change (Annex Figure A.2) for the restricted number of countries (Table A1). For these 12 countries appear to be in she-cession, and in 10 out of these 12 countries changes in gender shares of sectoral employment are the driving factor of the she-cession.

Figure 7: Decomposition of the COVID-19 Crisis's Absolute Gender Gap Change, 20192020:Q2

(Percentage points)

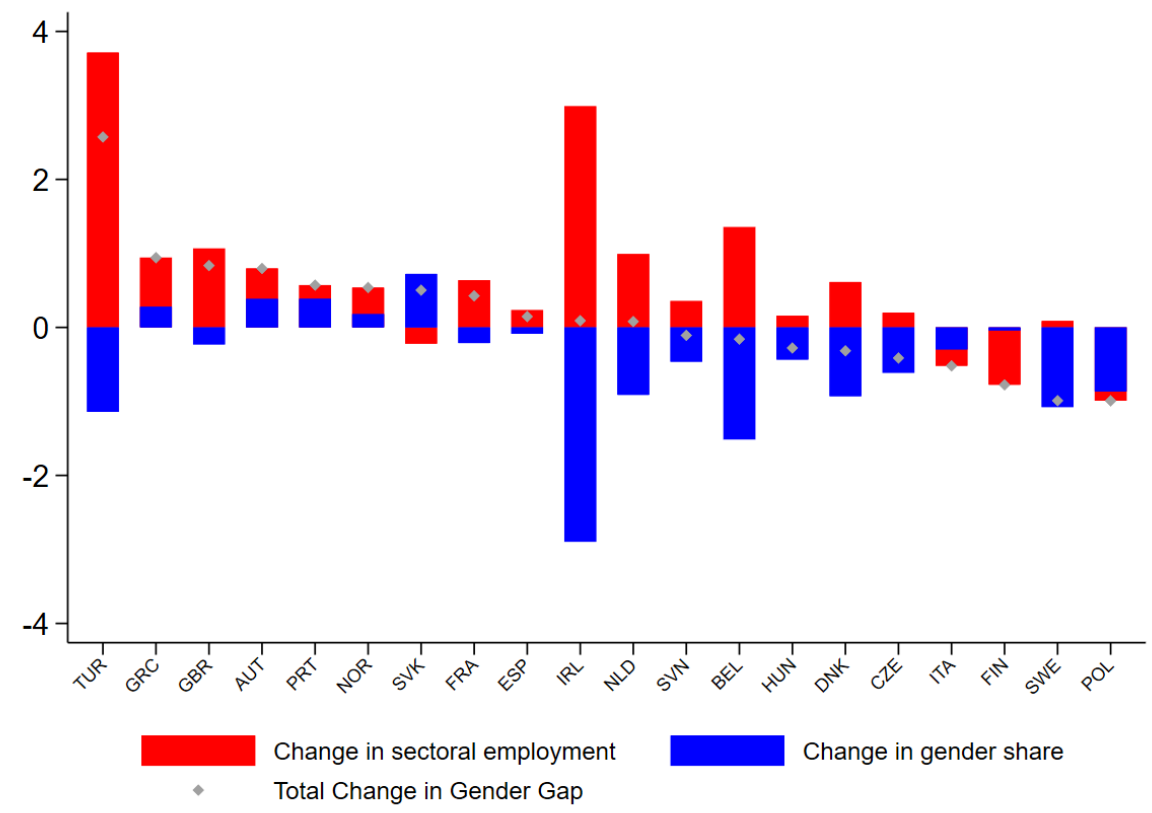

Note: The chart reports the two components which sum to the average gender gap change by country as defined by Equation (2). Based on restricted sample (Table A.1).

${ }^{4}$ For the decomposition of the gap from 2019 (average) to 2020:Q3 only 18 countries are included due to data availability for 2020:Q3. 


\section{Margins of LAbor Market Changes: Hours Worked, Unemployment, AND LABOR ForCE PARTICIPATION}

As mentioned in the introduction, the employment rate might miss some important aspects of labor markets' weakness, as it does not include workers that are still employed but experience cuts in working hours. To address this concern, we examine average hours worked, or the intensive margin of employment. Another important aspect is whether workers that are laid-off or quit their jobs look for a new job (unemployment), or they exit the labor force. As noted earlier, the literature has stressed that women have a higher average likelihood of exiting the labor force than men. If the COVID-19 recession has pushed women out of the labor force more than men, then focusing solely on the unemployment rate could understate the impacts on women, and as a result, the extent of she-cessions across countries. ${ }^{5}$

Contrary to our prior, men experienced a larger reduction in average hours worked than women in most countries, leading the median gender gap change for average hours worked relative to 2019 to rise (Figure 8, panel A). This average behavior also appears to be relatively common in the sample, with the $25^{\text {th }}$ percentile of the indicator well above zero. The implication is that the she-cessions are largely phenomena related to the extensive margin of employment.

As remarked earlier, the change in the employment rate is equal to the sum of changes in labor force participation rate minus changes in the unemployment rate (with some weights). When looking at these two indicators separately, it becomes clear that the she-cessions-as measured using the absolute gender gap change - tend to be more related to the relative declines in women's labor force participation than relative rises in their unemployment rates (Figure 8, panels $\mathrm{b}$ and $\mathrm{c}$ ). This becomes clear when the absolute gender gap change in employment rates is decomposed into these two margins - relative drops in women's labor force participation rate are more numerous and their contribution to negative gender gap changes in employment tend to be larger in magnitude than that from unemployment rises (Figure 9).

\footnotetext{
${ }^{5}$ Note that the analysis of hours worked uses the same sample of 20 countries as our decomposition exercise in Section 4 due to data availability.
} 
Figure 8: Absolute Gender Gap Changes in Labor Market Margins (Percentage points)

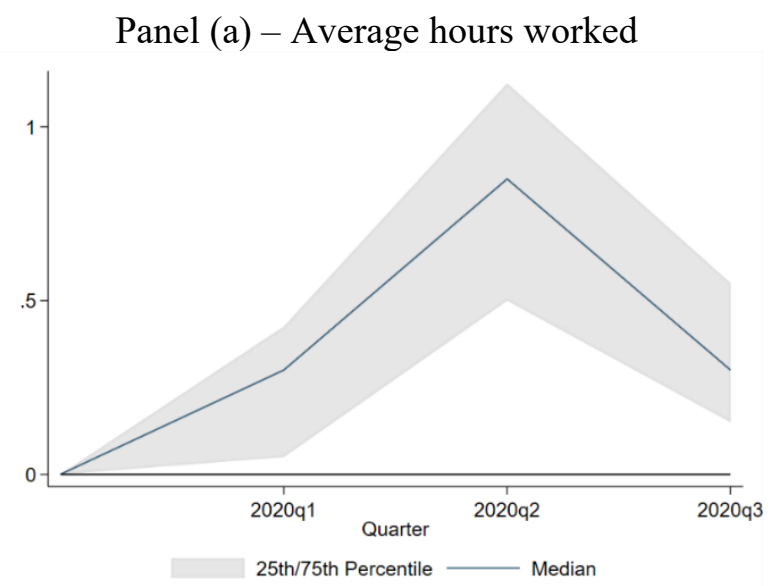

Panel (b) - Unemployment rate

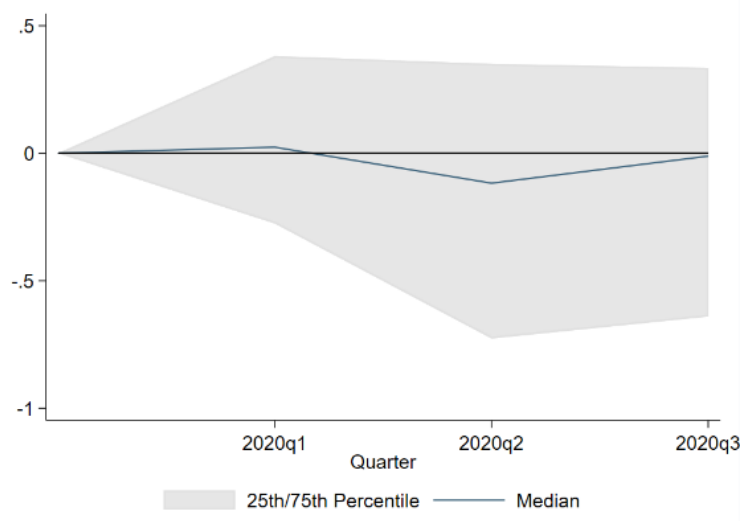

Panel (c) - Labor force participation rate

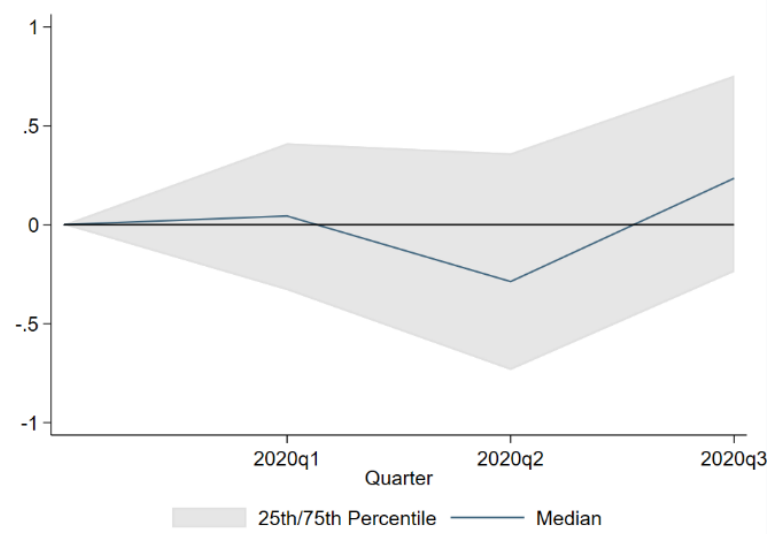

Note: The chart reports the evolution of the gap between women and men for three labor market outcomes with respect to the 2019 average. The solid line corresponds to the median and the shaded areas to the interquartile ranges. The sample includes 20 EU countries in panel (A) and the full sample of 38 advanced and emerging countries in panels (B) and (C). 
Figure 9: She-cession Absolute Gender Gap Change by Unemployment and Labor Force Participation Contributions

(Percentage points)

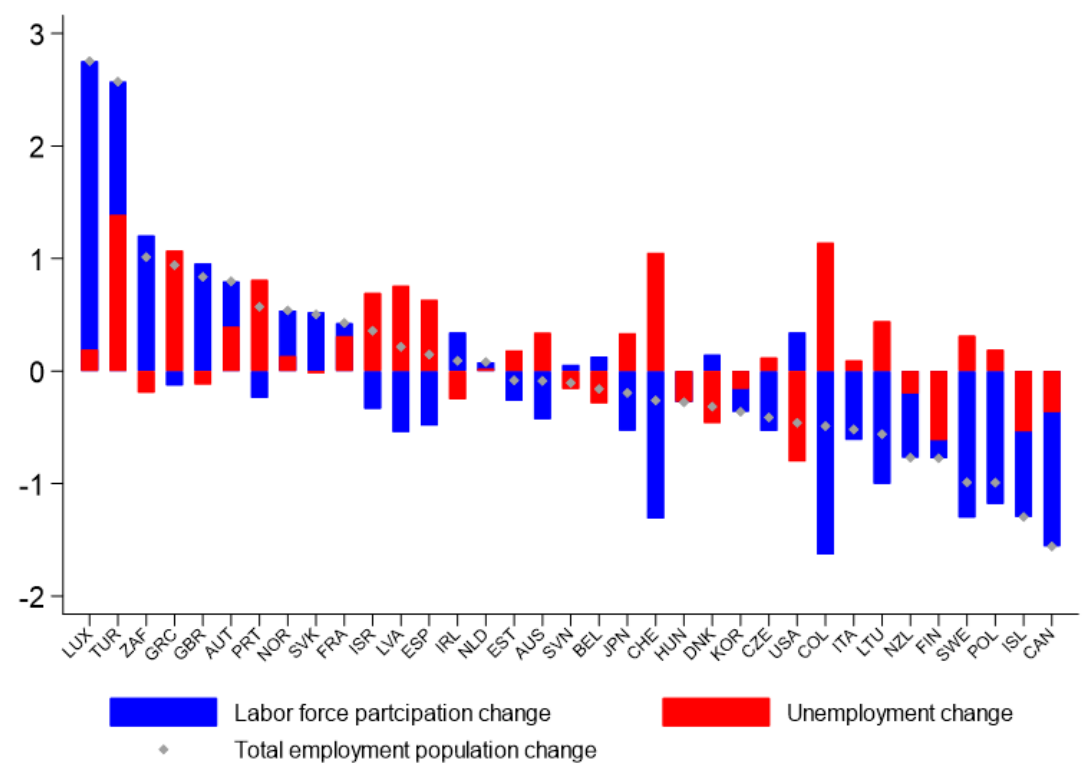

Note: The total absolute gender gap changes shown here correspond to Figure 2.

Examining other labor market indicators based on the relative gender gap change suggests similar patterns to the baseline seen with the absolute gender gap change-relative labor force participation fell on average in 2020:2, while the relative unemployment rate for women actually rose somewhat (Figure 10). Both patterns reverse by 2020:Q3 on average, Average hours worked also displays a similar pattern to the baseline, consistent with the extensive margin being most relevant for COVID19 she-cessions. 
Figure 10. Relative Gender Gap Changes in Labor Market Margins (Percent change)

Panel (a) - average hours worked

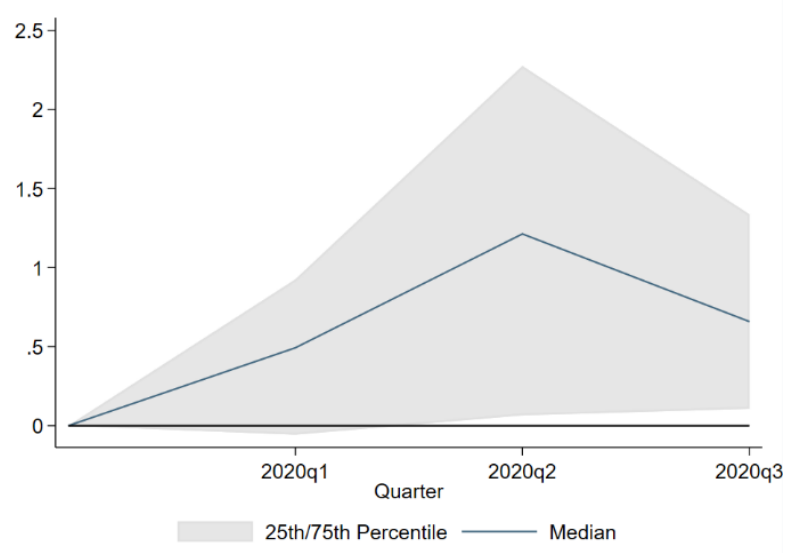

Panel (b) - unemployment rate

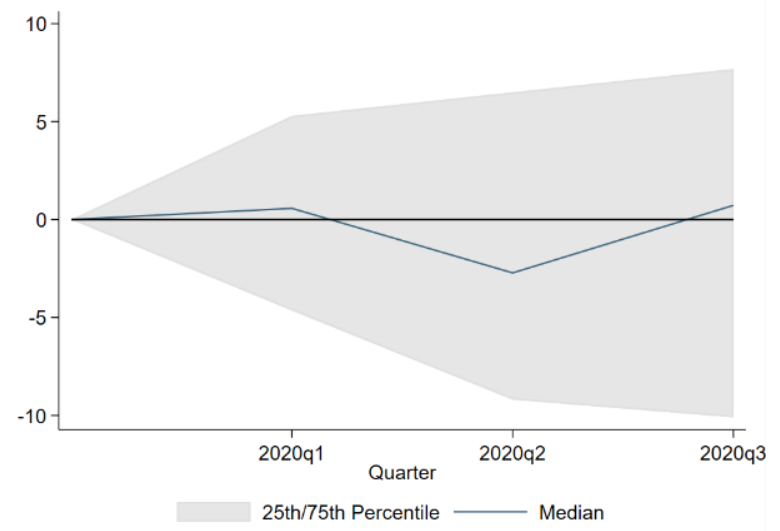

Panel (c) - labor force participation rate

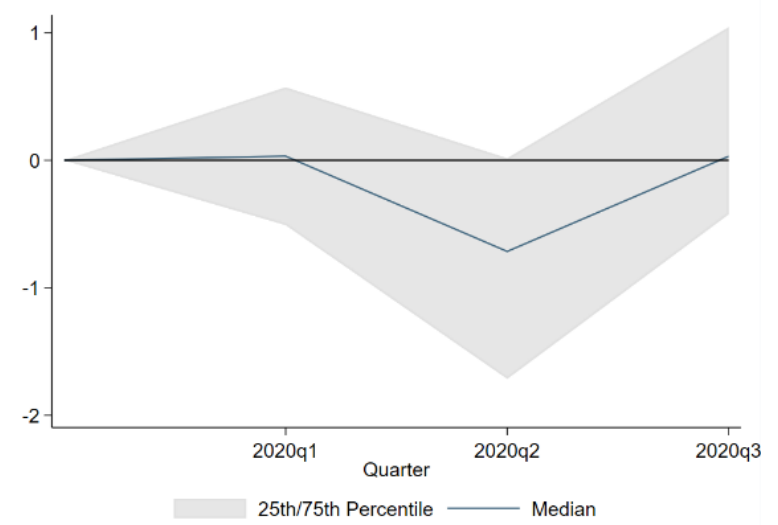

Note: The chart reports the evolution of the gap between women and men for four labor market outcomes with respect to the 2019 average. The solid line corresponds to the median and the shaded areas to the interquartile ranges. The sample includes 38 advanced and emerging countries in panels (b) and (c) whereas it includes 19 European union countries in panel (a). 


\section{Conclusion}

Unusual features of the COVID-19 pandemic recession-widespread lockdowns of the economy, school closures, and large hits to contact-intensive sectors-led to concerns of highly disproportionate, adverse impacts on women workers. Examining a large panel of 38 advanced economies and emerging markets through 2020, we find a high degree of heterogeneity across countries in the incidence and severity of she-cessions, where women's employment falls more than men's, with more than half to two-thirds of the countries experiencing a she-cession in 2020:Q2 (the trough of the pandemic recession). Moreover, she-cessions tend to be short-lived, with between threefifths to two-thirds of countries out of she-cession by 2020:Q3 (that is, preexisting gender gaps are not further worsening).

For countries where sectoral employment by gender is observed, she-cessions were predominantly driven by declining women's shares in employment within sectors. This is more important for sectors which account for more of women's employment.

COVID-19 she-cessions are also more clearly phenomena related to the extensive margin (employment), as the gender gap change in average hours worked actually rose on average (that is, for women who keep their jobs, their hours decline tended to be less than that of men). Moreover, much of the relative employment decline reflects women's greater propensity to exit the labor force than men, rather than a shift into outright unemployment. The relative drop in women's labor force participation could partly reflect the greater impact of the crisis on mothers, particularly those who are lower-income and lower-skilled, as childcare burdens increased with the crisis (Fabrizio, Gomes, and Tavares 2021).

Some of the cross-country differences in the gender gap changes with the COVID-19 recession may reflect deeper structural factors at play, including the gender composition of sectoral employment, the availability of affordable childcare alternatives, and employment regulations with differential impacts by gender. To reduce these gaps, policymakers could aim to ensure that affordable and reliable childcare options are available (whether privately or publicly provided), that family leave is available for equitable use by men and women (recognizing evolving gender roles), and that there is flexibility in work hours as job requirements allow. 


\section{References}

Adams-Prassl, A., Boneva, T.,Golin, M., and C. Rauh. 2020. "Inequality in the impact of the coronavirus shock: Evidence from real time surveys." Journal of Public Economics 189: 104245 .

Aisenbrey, S., Evertsson, and D. Grunow. 2009. "Is There a Career Penalty for Mothers' Time Out? A Comparison of Germany, Sweden, and the United States." Social Forces, 88 (2): $573-$ 605.

Albanesi, S., and J. Kim. 2021. "The Gendered Impact of the COVID-19 Recession on the US Labor Market.” NBER Working Papers 28505. National Bureau of Economic Research, Cambridge, MA.

Albrecht, J., P. Edin, M. Sundström, and S. Vroman. 1999. "Career Interruptions and Subsequent Earnings: A Reexamination Using Swedish Data.” Journal of Human Resources, 34 (2): 294-311.

Alon, T., M. Doepke, J. Olmstead-Rumsey, and M. Tertilt. 2020. "This Time It's Different: The Role of Women's Employment in a Pandemic Recession.” NBER Working Paper 27660. National Bureau of Economic Research, Cambridge, MA.

Bahn, K. and C. Sanchez Cumming. 2020. "How the coronavirus recession is impacting part-time U.S. workers." Equitable Growth (blog).

Blau, F. D. and L. M. Kahn. 2013. "Female Labor Supply: Why Is the United States Falling Behind?" American Economic Review 103 (3): 251-56.

Caselli, F., F. Grigoli, D. Sandri, and A. Spilimbergo. 2020. "Mobility under the COVID-19 Pandemic Asymmetric Effects across Gender and Age." IMF Working Paper 20/282. International Monetary Fund, Washington, DC.

Chetty, R., J. Friedman, N. Hendren, M. Stepner, and The Opportunity Insights Team. 2020. "The Economic Impacts of COVID-19: Evidence from a New Public Database Built Using Private Sector Data." NBER Working Paper 27431. National Bureau of Economic Research, Cambridge, MA.

Coibion, O., Y. Gorodnichenko, and M. Weber. 2020. "Labor Markets during the Covid-19 Crisis: A Preliminary View." NBER Working Paper 27017. National Bureau of Economic Research, Cambridge, MA.

Elborgh-Woytek, K., M. Newiak, K. Kochhar, S. Fabrizio, K. Kpodar, P. Wingender, B. Clements, and G. Schwartz. 2013. "Women, Work and the Economy: Macroeconomic Gains from Gender Equity.” Staff Discussion Note SDN13/10, International Monetary Fund, Washington. 
Fabrizio S., D. Gomes, and M. M. Tavares. 2021. "COVID-19 She-cession: The Employment Penalty of Taking Care of Young Children.” IMF Working Paper 21/55. International Monetary Fund, Washington, DC.

Fuchs-Schündeln, N., D. Krueger, A. Ludwig, and I. Popova. 2020. "The Long-Term Distributional and Welfare Effects of COVID-19 School Closures.” NBER Working Paper 27773. National Bureau of Economic Research, Cambridge, MA.

Goldin, C. 2015. "How to Achieve Gender Equality.” Milken Institute Review, 2015 (Q3): 24-33.

Gonzales, C., S. Jain-Chandra, K. Kochhar, M. Newiak, and T. Zeinullayev. 2015a. "Catalyst for Change: Empowering Women and Tackling Income Inequality.” Staff Discussion Note SDN/15/20, International Monetary Fund, Washington.

Giupponi, G. and C. Landais. 2020. "Building Effective Short-term Work Schemes for the COVID-19 Crisis." VoxEU (blog).

Hoynes, H., D. Miller, and J. Schaller. 2012. "Who Suffers During Recessions?" Journal of Economic Perspectives, 26 (3): 27-48.

Hupkau, C. and B. Petrongolo. 2020. "Work, Care, and Gender During the COVID-19 Crisis." Fiscal Studies, 41 (3): 623-51.

International Monetary Fund (IMF). 2021. "Recessions and Recoveries in Labor Markets: Patterns, Policies, and Responding to the COVID-19 Shock." In World Economic Outlook April 2021.

Mongey, S., L. Pilossoph, and A. Weinberg. 2020. "Which Workers Bear the Burden of Social Distancing Policies?” NBER Working Paper 27085. National Bureau of Economic Research, Cambridge, MA.

Petrongolo, B. 2004. "Gender Segregation in Employment Contracts." Journal of the European Economic Association, 2: 331-45.

Romei, V. 2021. "I am close to quitting my career': Mothers step back at work to cope with pandemic parenting," available at https://www.ft.com/content/d5d01 f06-9f7c-4cdc-9fee$225 \mathrm{e} 15 \mathrm{~b} 5750 \mathrm{~b}$

Russell, L., and C. Sun. 2020. "The effect of mandatory childcare center closures on women's labor market outcomes during the COVID-19 pandemic." Covid Economics 62: 124-54.

Shibata, I. 2020. "The Distributional Impact of Recessions: The Global Financial Crisis and The Pandemic Recession.” IMF Working Paper 20/96. International Monetary Fund, Washington, DC.

Vuri, D. 2016. “Do Childcare Policies Increase Maternal Employment?” IZA World of Labor, 2016 (March): 241. 
Wall, H. 2009. “The Man-Cession of 2008-09: It's Big, But It's Not Great.” The Regional Economist. 2009 (October): 4-9.

Zamarro, G., and M. Prados. 2021. "Gender Differences in Couple's Division of Childcare, Work and Mental Health." Review of Economics of the Household 19: 11-40. 
Table A1. List of countries by section

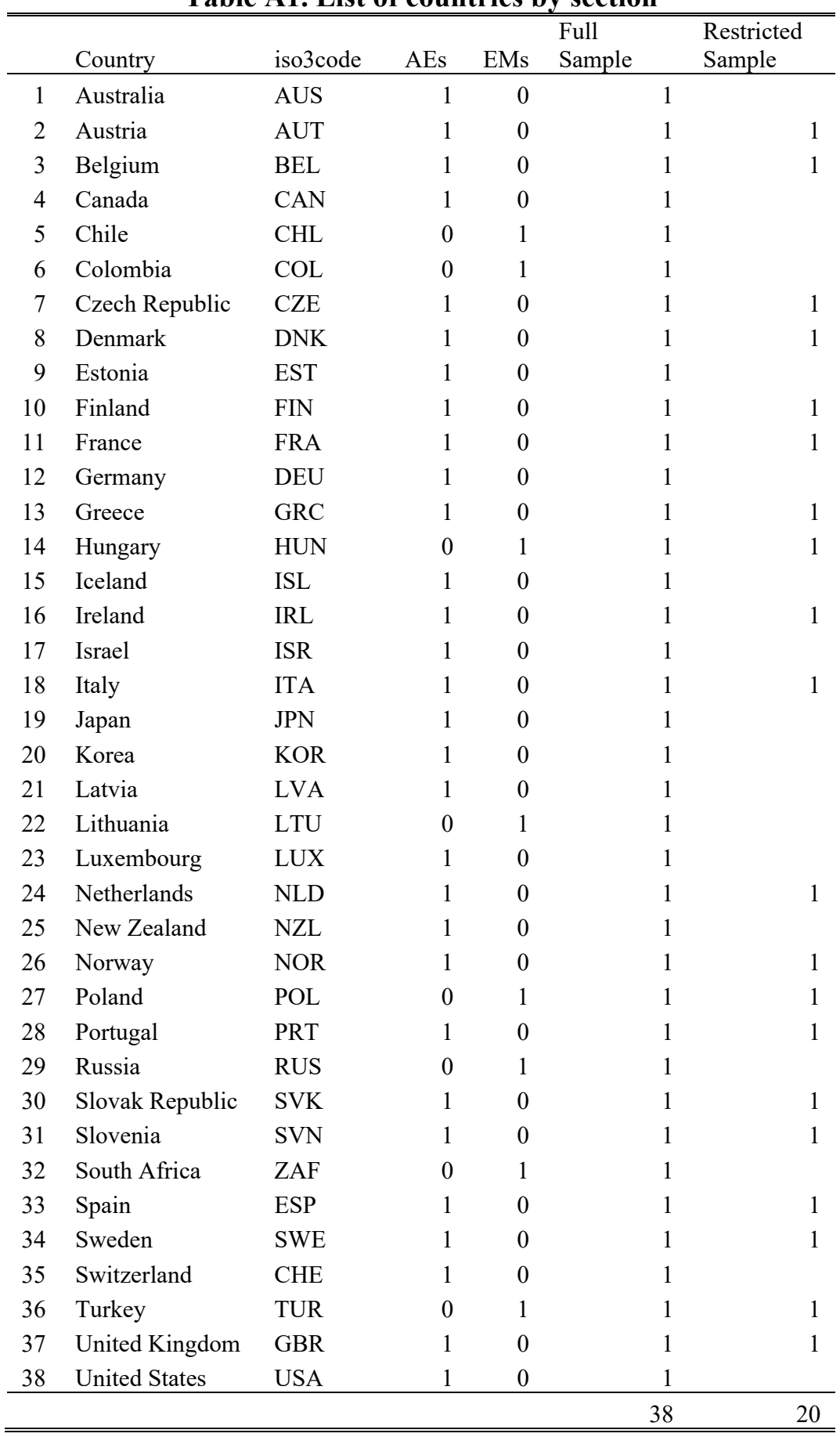




\section{ANNEX: ROBUSTNESS ON THE ROLE OF SECTORAL WORKFORCE COMPOSITION}

In this annex we conduct two robustness checks of the decomposition exercise conducted in Section IV of the main paper. First, we decompose the total change in the gender gap from 2019 (average) to 2020:Q3 rather than from 2019 (average) to 2020:Q2 as done in Section IV of the main text. Second, we decompose the change in the total gender gap from 2019 (average) to using 2020:Q2 using the relative gender gap change.

Figure A1 shows the decomposition of the absolute change in the gender gap from 2019 to 2020:Q3 for each country in our sample. The grey dot corresponds to the gender gap change, the blue bar to the component due to the change in gender share, and the red one to the component due to the change in sectoral employment. A negative value in this chart indicates that the relevant factor contributed to a more negative impact for women than for men, while a positive factor means that the relevant factor contributed to a more negative impact for men than women. For this period 7 out of 18 countries (instead of 9 out of 20 counties) appear to be in she-cession - that is, the change in the overall gender gap in employment rates is negative. ${ }^{6}$ In 5 countries out of these 7 countries, changes in gender shares of sectoral employment are the driving factor of the she-cession.

Figure A1: Sectoral Decomposition of the Absolute Gender Gap Change, 2019-2020:Q3 (percentage points)

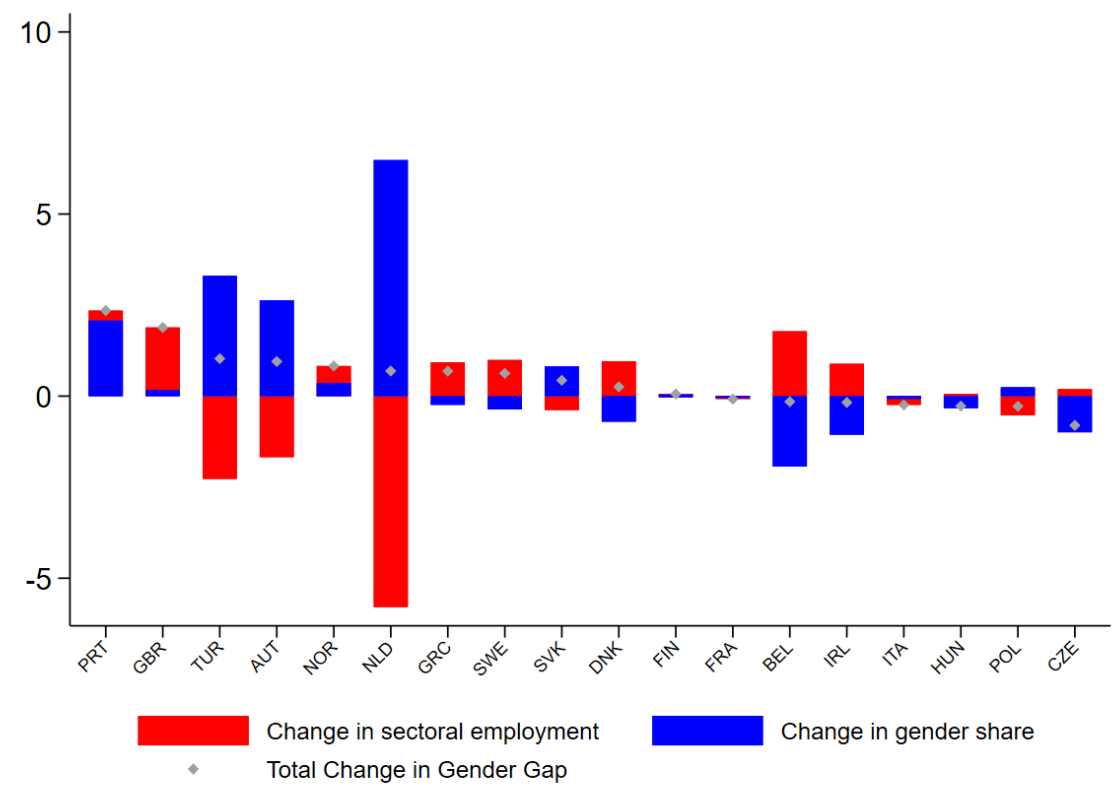

Note: The chart reports the two components which sum to the average gender gap change by country as defined by Equation (2). Based on restricted sample (Table A.1).

Figure A2 shows the decomposition of the relative change in the gender gap from 2019 to 2020:Q2 using the relative gender gap change from equation (2). This alternative gender gap is decomposed into changes stemming from (i) the change in sectoral employment, and (ii) the change in gender share using the equation in (A.1).

\footnotetext{
${ }^{6}$ For Figure A2 only 18 countries are included due to data availability for 2020:Q3.
} 


$$
\begin{aligned}
\left(e_{t+1}^{w}-e_{t}^{w}\right) / e_{t}^{w} & -\left(e_{t+1}^{m}-e_{t}^{m}\right) / e_{t}^{m} \\
& =\left[\left(e_{t+1}^{w}-\sum_{s} \omega_{s, t}\left(\frac{E_{s, t+1}}{P_{t+1}^{w}}\right)\right)-\left(e_{t}^{w}-\sum_{s} \omega_{s, t}\left(\frac{E_{s, t+1}}{P_{t+1}^{w}}\right)\right)\right] / e_{t}^{w} \\
& -\left[\left(e_{t+1}^{m}-\sum_{s}\left(1-\omega_{s, t}\right)\left(\frac{E_{s, t+1}}{P_{t+1}^{m}}\right)\right)-\left(e_{t}^{m}-\sum_{s}\left(1-\omega_{s, t}\right)\left(\frac{E_{s, t+1}}{P_{t+1}^{m}}\right)\right)\right] / e_{t}^{m} \\
& =\underbrace{\left[\frac{\left(\sum_{s} \omega_{s, t}\left(\frac{E_{s, t+1}}{P_{t+1}^{w}}-\frac{E_{s, t}}{P_{t}^{w}}\right)\right)}{e_{t}^{w}}-\frac{\left(\sum_{s}\left(1-\omega_{s, t}\right)\left(\frac{E_{s, t+1}}{P_{t+1}^{m}}-\frac{E_{s, t}}{P_{t}^{m}}\right)\right)}{e_{t}^{m}}\right]}_{\text {change in sectoral employment }} \\
& +\underbrace{\left[\left(\sum_{s}\left(\omega_{s, t+1}-\omega_{s, t}\right)\left(\frac{E_{s, t+1}}{P_{t+1}^{w}}\right)\right)\right.}_{\text {change in gender share }}-\frac{\left(\sum_{s}\left(\omega_{s, t}-\omega_{s, t+1}\right)\left(\frac{E_{s, t+1}}{P_{t+1}^{m}}\right)\right)}{e_{t}^{w}}]
\end{aligned}
$$

where variables are notated similarly to in Section IV of the main text. According to Figure A.2, 12 out of 20 countries appear to be in she-cession. In 10 countries out of these 12 countries, changes in gender shares of sectoral employment are the driving factor of the she-cession.

Figure A2: Sectoral Decomposition of the Relative Gender Gap Change, 2019-2020:Q2 (percentage points)

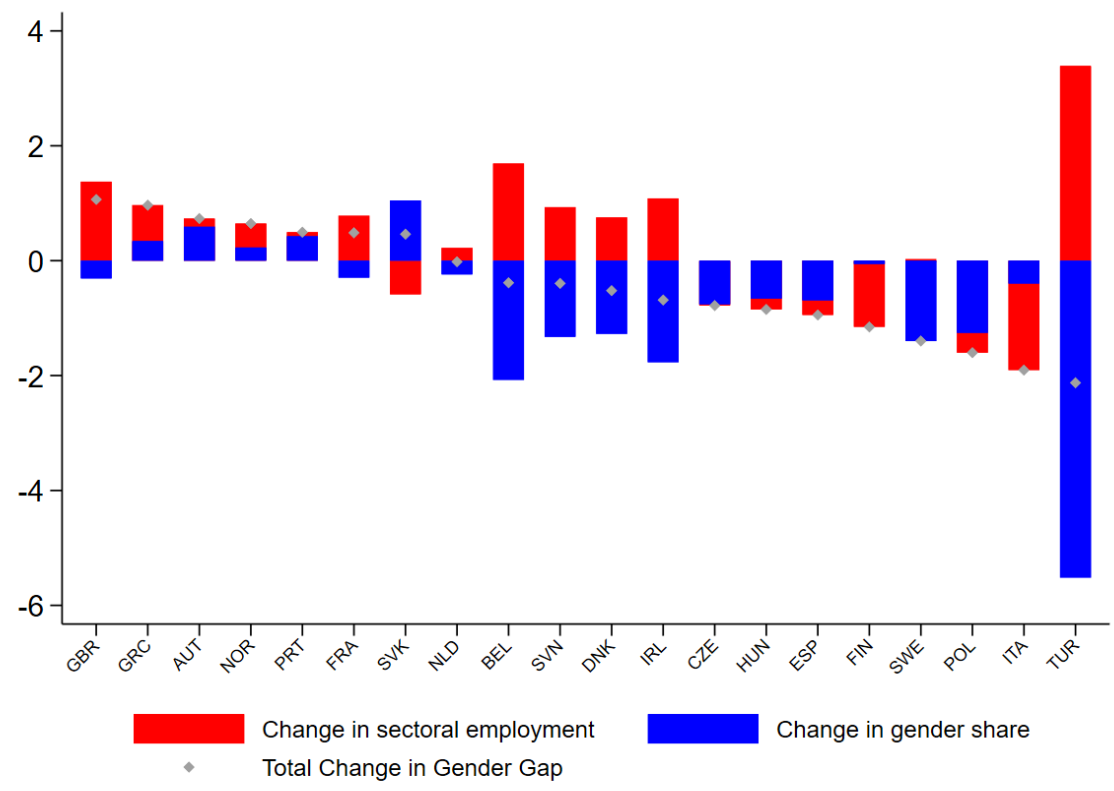

Note: The chart reports the two components which sum to the average gender gap change by country as defined by Equation (2). Based on restricted sample (Table A.1). 